\title{
Integrating Abaca in a Mixed Forest Culture: A Livelihood Option for Smallholder Tree Farmers ${ }^{1}$
}

\author{
Lelita R. Gonzal \\ National Abaca Research Centre \\ Visayas State University, Visca, Baybay \\ Leyte, the Philippines
}

\begin{abstract}
This paper discuses the economic and ecological benefits of integrating abaca in established monoculture fruit trees and mixed forest culture, especially rainforestation farming. Integration of agricultural crops with high tolerance to shade, that will provide additional income to farmers and preserve the environment, is one of the key elements of a sustainable tree farming system. Inclusion of natural fibre plants such as abaca, a natural shade-loving plant, to the smallholder tree farming system will not only provide income opportunities to the farmers but also prevent soil erosion and conserve forest water. However, precautionary measures must be undertaken not to overshade the abaca since overshading causes the production of weak fibre. Integrating abaca in established monoculture fruit trees and mixed forest culture especially rainforestation farming is found to have a number of economic and ecological benefits.
\end{abstract}

Keywords: rainforest farming, shade tolerance, intercropping, return on investment

\section{INTRODUCTION}

One of the key elements of a sustainable tree farming system is to integrate agricultural crops which have a high degree of tolerance to shade, will provide income opportunities and preserve the environment at the same time. Given that income generation through timber production typically takes about 10 or more years, smallholder tree farmers should generate income from non-wood products to support their daily needs in the short term. Agricultural activities must promote soil

\footnotetext{
${ }^{1}$ An earlier version of this paper was presented at the planning workshop of the Australian Centre for International Agricultural Research (ACIAR) project ASEM/2003/052, Improving Financial Returns to Smallholder Tree Farmers in the Philippines, held at the Sabin Resort Hotel in Ormoc City, Leyte Province, the Philippines, on 15-17 February 2005.

Dol: 10.32945/atr2932.2007
} 
conservation and recovery to ensure its short and long-term capacities to support crop growth and productivity.

Natural fibres such as abaca (Musa textilis) are becoming more and more important as industrial raw materials because of the economic and ecological benefits they bring. Abaca thrives even in the shade beneath tall trees. This plant, when intercropped with timber and fruit trees, is not only a source of income but also prevents soil erosion and conserves forest water. In 1997, the Department of Environment and Natural Resources (DENR) included abaca fibre production and utilisation as one of the sustainable livelihood options for the upland ecosystem in the Philippines.

Abaca is a natural shade loving plant. It is indigenous to the Philippines and most of the clones now in cultivation originated from mountain slope areas of Mindanao, Samar, Leyte and Bicol. As with most sciophytes, exposure to intense sunlight in new open land causes slow growth and even the death of abaca plants during the first three years. As a remedial measure, trees are planted with abaca to provide shade. Overshading, however, results in weakening of the fibre.

Abaca is grown primarily for its fibre which is utilised for the pulp, cordage and in fibrecraft industries. As one of the major industrial crops, it continues to be one of the important sources of employment and foreign exchange earnings of the Philippines. It remains a potent export crop because of the wide range of uses, particularly in the manufacture of tea bags, meat casing, currency notes, cigarette filter paper, cable insulation and a host of other industrial products. The specific tensile strength of the fibre is comparable or even higher than fibreglass, hence it can be used as substitute for glass fibre in the manufacture of reinforced plastics for various technical applications.

An added benefit of integrating agricultural crops between tree crops is the greater willingness of farmers to protect the area from fire compared with when a site is planted with forest tree species only. This is largely due to the fact that, if the farmer is dependent on agricultural crops for subsistence and income, it is their immediate interest to protect them (and thus the tree species) from fire. For instance, in Nagtimog, Diadi, Nueva Viscaya, Philippines, the farmers constructed fire lines and planted bananas around their agricultural and forest tree crops as a protective belt. Being a succulent plant, abaca contains a high amount of water, and can be used as fire lines to control the spread of fire in the adjacent timber plantation.

\section{ECONOMIC AND ECOLOGICAL SIGNIFICANCE OF ABACA IN THE PHILIPPINES}

Like timber and fuelwood, abaca fibre is in high demand. Current fibre production is not enough to meet the fibre requirement for both the Philippine and foreign markets. About $69.2 \%$ of the total abaca fibre produced is consumed locally and the rest is exported to the United Kingdom, Japan and the USA, the major fibre importing countries which accounted for $53.3 \%, 34 \%$ and $6.5 \%$ shares of the fibres exported, respectively (FIDA 2005). For the pulp, Germany, UK, Japan and France are the leading markets, while USA, UK and Singapore are the top importers of cordage. As more abaca-based industrial products are discovered due to the superior fibre qualities, 
the demand for abaca fibres is expected to increase. Thus, the abaca industry will continue to gain a stronghold in both the domestic and international markets.

Abaca can be grown using a zero tillage system. It does not require intensive land preparation. It is a shade-loving plant and grows vigorously under canopy of forest trees. Thus, not much clearing or other disturbance is done to the ecosystem. Most abaca farmers do not use synthetic fertilisers, thereby maintaining the natural soil ecosystem and minimising groundwater pollution. Moreover, the fibres extracted from abaca stalks are the strongest among natural fibres and can be substituted to syntheticbased nylon, plastics and other non-biodegradable materials. To avoid encroachment of the natural forests by upland dwellers, specifically abaca farmers, abaca should be grown in harmony with the Community-based Forest Management program of the DENR.

\section{INTEGRATING ABACA IN A MIXED-FOREST CULTURE}

\section{Rainforest Farming Integration}

The productivity of a crop becomes increasingly sustainable the closer it is grown to its natural habitat. Abaca, being a shade loving plant, typically grows better in mountainous areas in association with various forest species, rather than in lowland areas. Presently, abaca is grown in monoculture plantations in secondary forests or logged-over areas and under coconut plantations. It is frequently the source of cash income for poorer households who have abaca as a single cash crop together with various subsistence crops (Lacuna-Richman 2002).

In the traditional practice, the establishment of an abaca crop is usually the last stage before forest encroaches on agriculture. However, abaca plants are long-lived perennials and the same families have maintained the area planted to abaca for many years. Thus, abaca can be considered an ideal crop for forest edge households in Leyte, and in other abaca growing areas.

According to Asio and Milan (2002), rainforestation farming is an innovative approach to rehabilitate degraded lands and old coconut stands, restore forest vegetation and improve soil quality. It provides an opportunity to earn income from an area that is no longer economically productive while at the same time producing timber of high quality. If the present land-use management is gradually replaced by a system that is ecologically sound, the preservation of nature and stabilisation of an adequate subsistence farm income can be achieved. Integration of the production of abaca fibre which is highly in demand for the manufacture of various industrial products into the system could provide a sustainable source of income not only for smallholder tree farmers but also to the local fibre processing industry, and hence could lead to the alleviation of rural poverty.

Bande (2004) reported that abaca is a highly suitable crop for integration in rainforestation farming and monoculture coconut growing, by creating a diversified multistrata agroecosystem (Figures 1-3). The integration of abaca in the rainforestation farming concept will serve as a guide for transforming the actual subsistence level single species system into holistic community-based rainforestation farming. The produce from fruit and forest trees (as listed listed in Table 1) could allow abaca-producing households to earn an income when harvesting the fibre 
becomes impossible or income from fibre can support the family when produce from fruits and forest trees are not available. He further stressed that if sustainability of the whole agroecosystem function is taken into consideration, integrating abaca into the rainforestation farming concept is a preferred option. Trees play an important role in the nutrient fluxes and reduction in soil acidity in the surface horizon. Trees function as 'nutrient pumps' contributing to the high degree of nutrient uptake to the abaca leaves.

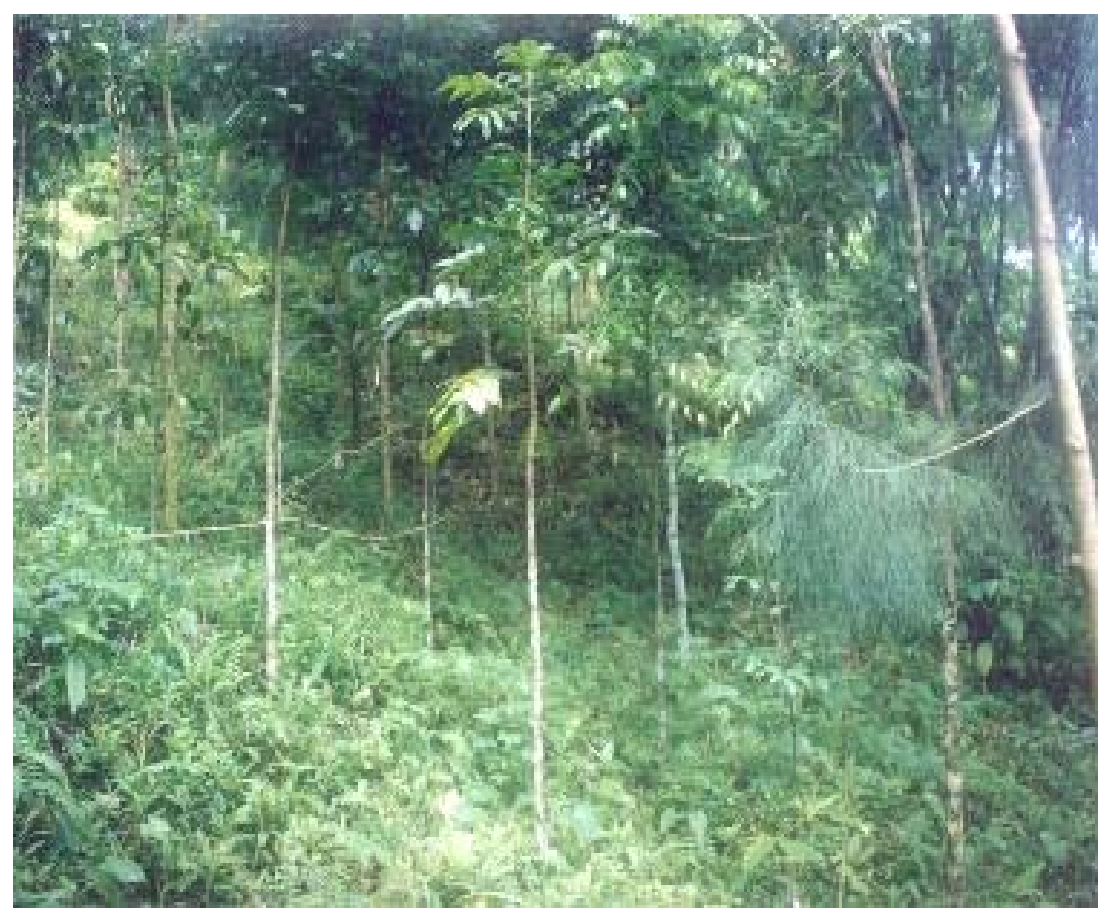

Figure 1. Rainforestation farm in Brgy. Mailhi, Baybay, Leyte before planting abaca

Note: The 1.2 ha site was originally a 10 -year old rainforestation farm. Some of the nursed trees could now be harvested, which would greatly improve light penetration to the understorey dipterocarp and fruit tree species. 


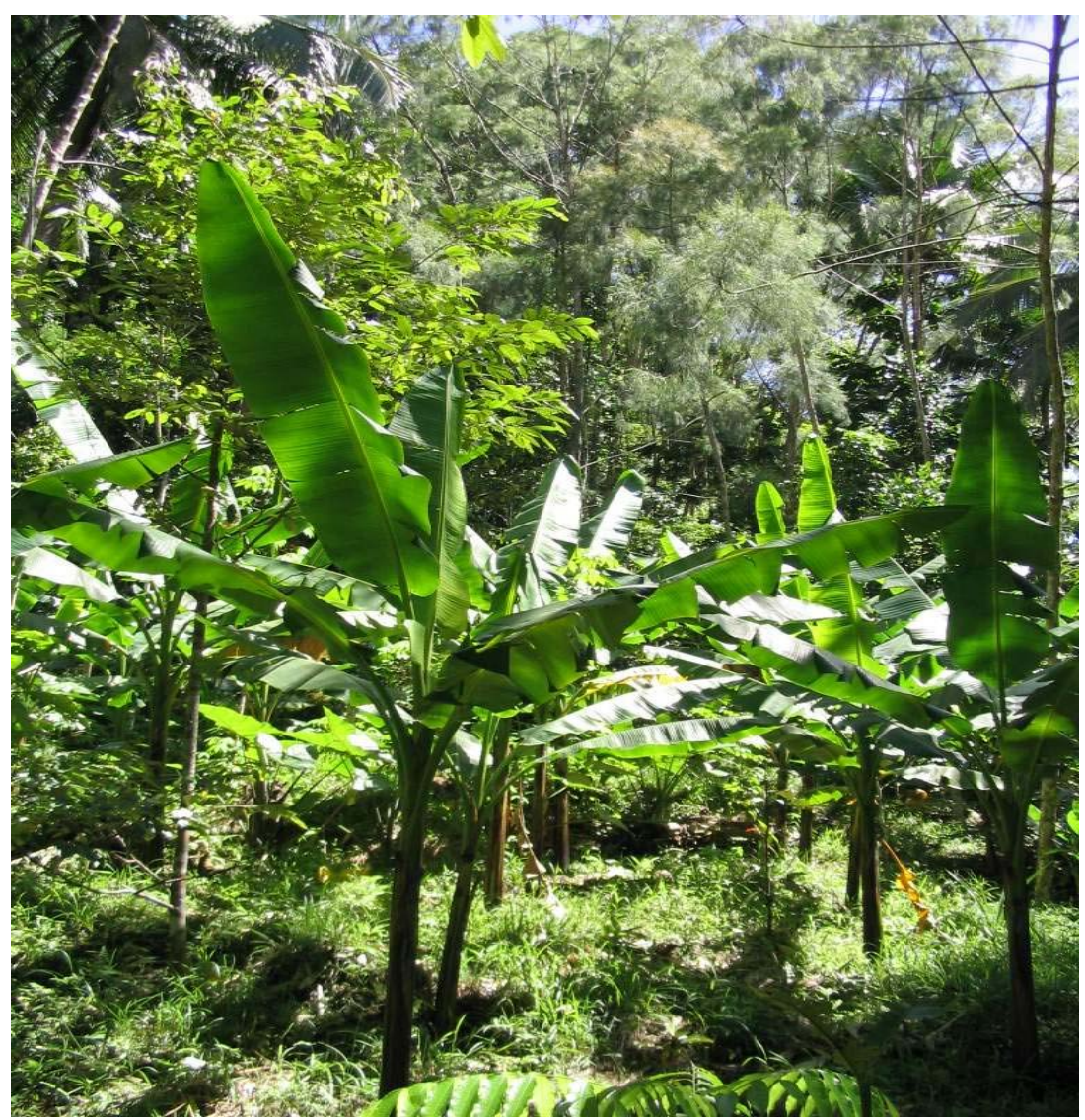

Figure 2. Rainforestation farm in Brgy. Mailhi, Baybay, Leyte, one year after planting abaca 
Table 1. Tree type, and common and scientific names

\begin{tabular}{lll}
\hline Tree type & \multicolumn{1}{c}{ Common name } & \multicolumn{1}{c}{ Scientific name } \\
\hline Non-dipterocarps & Mountain agoho & Casuarina rumphiana \\
& Dao & Dracontomelon dao \\
& Kalumpit & Terminalia microcarpa \\
& Malakawayan & Podocarpus imbricatus \\
& Tamayuan & Strombosia philippinensis \\
& Almaciga & Agathis philippinensis \\
& Narra & Pterocarpus indicus \\
\hline Dipterocarps & White Lauan & Shorea contorta \\
& Bagtikan & Parashorea malaanonan \\
& Dalingdingan & Hopea Foxworthy \\
& Hagakhak & Dipterocarpus warburgii \\
\hline Fruit trees & Lansones & Lansium domesticum \\
& Rambutan & Nephelium lappaceum \\
& Durian & Durio zibethinus \\
& Mangosteen & Garcinia mangostana \\
& Jackfruit & Artocarpus heterphylla \\
\hline
\end{tabular}

\section{Coconut Integration}

Cutting down coconut trees on a large scale has created vast open lands that are either left idle for a long period or planted with cash crops including cassava, sweetpotato, corn and upland rice. This type of farming system causes severe soil erosion especially on steep sites, which not only reduces soil fertility but also causes sedimentation.

Various large-leafed species of pioneer trees and bushes can be planted, under which can be grown high quality indigenous tropical hardwood trees and fruit trees. Natural fibres including abaca can now be integrated to provide income opportunities for the farmers. Utilising the open space between monoculture coconuts will minimise further forest encroachment and clearing of tropical forest for abaca plantation. 


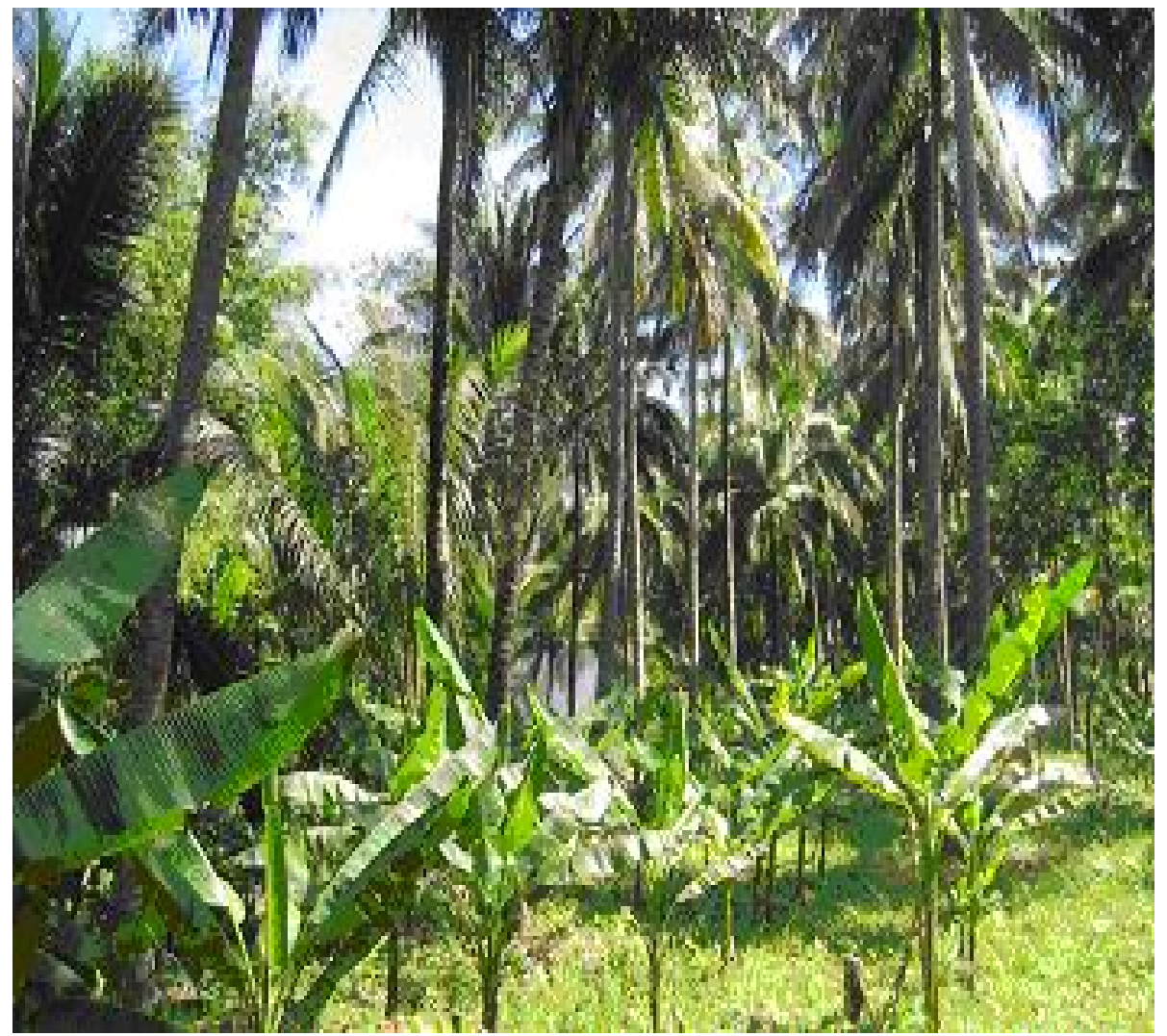

Figure 3. Integrating abaca with coconuts at Brgy. Caridad, Baybay, Leyte

Note: The site is a 40-year old monoculture coconut plantation with declining productivity. Thus, abaca plants were intercropped between coconuts to increase the income that would be derived from the area. 
On land managed by the Philippines National Oil Corporation (PNOC), near Ormoc City, exotic tree species namely Acacia mangium and Acacia auriculiformis have been used to reforest Imperata grassland. Abaca plants were then intercropped between the exotic tree species to serve as alternative source of income for the farmers. Abaca has performed well under the tree species primarily because the acacias are nitrogen-fixers. Nitrogen-fixing species improve the soil nutrient status and, through litter fall, increase soil organic matter content and enhance chemical and microbiological processes in the soil. These favourable effects substantially improve the growth of abaca under the plantation. However, according to Margraf and Milan (1996), using exotic trees as reforestation species does not support the protection and preservation of the remaining natural forest but rather indirectly contributes to deforestation and the drastic reduction of biodiversity for several reasons:

- fast growing exotic trees have low wood quality, hence high quality rainforest tree still need to be harvested in their natural environment;

- the monoculture of exotic trees does not support the survival of wildlife species of the local rainforest, some of which are important pollinators and distributors of seeds;

- the fast growing exotics are all pioneer species with a short life span which support a management of repeated clear cutting; and

- local lumber species, even though their timber quality is much higher, are not highly regarded by farmers, and consequently are cut but not propagated.

Therefore, conversion of natural or logged-over areas into monoculture of fastgrowing tree species (exotic or native) cannot be considered as a form of sustainable management (Schults 1996).

\section{Fruit Tree Integration in Hilly Areas}

Shade is indispensable to the successful culture of abaca. Woody perennials used as partial shade to abaca increase fibre production by stimulating robust growth and sucker production (Anon 1991). Anii (Erythrinia fusca) is the most common natural shade tree found in abaca plantations. However, except for fuelwood, using this species does not provide additional benefits to the farmers. If economically important tree species such as fruit trees can be grown as companion trees to abaca, this will provide upland farmers not only with higher growth and yield of abaca but also with an added source of income.

In their study on intercropping abaca with established fruit trees, Gonzal and Briones (2004) reported that in addition to the income from the sale of fruit, the farmers are able to derive additional benefits from the fruit trees including fuelwood, timber, dye and traditional medicine, as listed in Table 2. 
Table 2. Fruit tree species grown with abaca

\begin{tabular}{lll}
\hline Common name & Scientific name & Benefits/purpose \\
\hline Durian & Durio zibethinus & Fr, Fw, Tm \\
Lanzones & Lansium domesticum & Fr, Fw, M \\
Citrus (calamansi) & Citrus microcarpia & Fr, M \\
Rambutan & Nephelium lappaceum & Fr, Fw, M, D \\
Mango & Magnifera indica & Fr, Fw, M \\
Cacao (Plantation crop) & Theobrama cacao & Fr, Fw, M \\
\hline
\end{tabular}

Note: Fr - fruit; Fw - fuelwood; Tm - timber; M - medicine; D - dye.

Among the fruit tree species used, mango and durian have the tendency to grow to a great height and produce branches with dense foliage. Hence, measures such as pruning have to be undertaken so as not to overshade the abaca.

Cost and return analysis of interplanting abaca with established fruit trees showed that abaca-mango gave the highest net return followed by durian-abaca with P330,127 and P138,436 net income and a return on investment (ROI) of 4.88 and $7.14 \%$, respectively. Although abaca intercropped with cacao had the highest fibre yields, the total net income derived from both plants was still lower than the other abaca-fruit tree combinations. Moreover, fruit trees-abaca integration improved the surface soil acidity and organic matter content of the soil.

Processing of abaca wastes such as the outer leafsheath and stripping wastes into high-value products opens up employment opportunities not only to the farmers' household members but also to the other idle members of the community. Women, out-of-school youth and other members of the community can engage in handicraft making using the abaca wastes to generate additional income for the family.

\section{CONCLUDING COMMENTS}

Undoubtedly, the integration of abaca into rainforestation systems, monoculture coconut, fruit trees and fast growing exotic tree species provides income opportunities for smallholder tree farmers. However, if sustainability of the whole ecosystem function is taken into consideration, integrating abaca into rainforestation farming is the best option. The closer the farming system in the humid tropics is to a natural rainforest ecosystem, the greater is the sustainablity. Hence, productivity of a crop becomes increasingly sustainable the closer it is to its natural habitat.

\section{REFERENCES}

ASIO, V. and P.P. MILAN. 2002. Improvement of soil quality in degraded lands through rainforestation farming. A paper presented at the International Symposium on Sustaining Food Security and Managing Natural Resources in Southeast Asia: Challenges for 21st Century, 8-11 January 2002. Chiang Mai, Thailand.

BANDE, M.M. 2004. Development of Sustainable Abaca (Musa textiles Nee) Production in a Diversified Multi-strata Agroecosystem in Leyte, the Philippines. MS Thesis, University of Hohenheim, Stuttgart, Germany. 
DENR (DEPARTMENT OF ENVIRONMENT AND NATURAL RESOURCES). 1997. Sustainable livelihood options for the Philippines. Upland Ecosystem Information Kit, Quezon City.

FIDA (THE FIBER INDUSTRY DEVELOPMENT AUTHORITY). 2005. Fibre Statistical Bulletin. DENR, Tacloban.

GONZAL, L.R. and R.L. BRIONES. 2004. Identification of ecologically important tree species as shade to abaca. Philippines Journal of Crop Science. Supplement number 1.

LACUNA-RICHMAN, C. 2002. The role of abaca in the household economy of a forest village. Small-scale Forest Economics, Management and Policy. 1(1): 93-101.

MARGRAF, J. and P.P. MILAN. 1996. Ecology of Dipterocarp forests and its relevance for island rehabilitation in Leyte, the Philippines. In: Dipterocarp Forest Ecosystems: Toward Sustainable Management (A. Schults and D. Shone, eds). World Scientific, Singapore, London.

SCHULTS, A. 1997. Monoculture of fast-growing Exotics versus reforestation with native species: theoretical aspects and experiences in the Dipterocarp Region. In: Reforestation with Philippines Species for Biodiversity Protection (J. Margraf, F. Göltenboth and P.P. Milan, eds). Proceedings from International Conference, VISCA, Baybay, Leyte, the Philippines. 